\title{
The future of regenerative medicine and tissue repair in the diabetic patient
}

\author{
Gerit Mulder* \\ Department of Surgery and Orthopedics, University of California San Diego, USA
}

The interest in and use of regenerative matrices and products for tissue repair has grown significantly over the last three decades. Initial developments at the end of the last century, focused on advanced wound dressing materials, simple collagen matrices and cell constructs predominantly with human derived fibroblasts and keratinocytes. The latter products were developed with the intent creating an environment designed to improve and expedite healing in chronic and problematic wounds. More recent advances have been made in the use of modified allografts and xenografts.

Diabetic patients have been of significant priority as a result of the associated high rate of morbidity and mortality, particularly lower extremity amputations, frequently result in from an initial ulceration of the skin. The diabetic healing process is already complicated by the disease state including altered or absent function of essential cytokines and cells required for normal soft tissue healing. The overwhelming number of products developed, have been either variations of wound dressings, or devices designed to assist with tissue repair. These products have fallen short of addressing the need for a sustainable and viable tissue replacement for skin defects requiring a combination of viable living cells, signal proteins, adhesion molecules and cytokines integrated into a matrix designed to sustain tissue repair activity. Currently, no optimal product exists which provides all of the needed qualities while being able to resist rapid degeneration rendering the product ineffective in the hostile environment of the diabetic wound. Repetitive trauma to the wound site, infection and difficulty in consistently off-loading the diabetic foot further reduce efficacy.

There is a very significant need for a stable, durable and viable matrix that has numerous ideal characteristics, including but not limited to: a long shelf life not requiring cryopreservation or a tightly controlled storage environment, a high level of cell viability at the time of application, the ability to deliver cytokines and signal proteins, capability of ring remain intact and functional in a chronic and sometimes bacterially contaminated environment, and be designed to be replaced by host tissue.

This decade has seen the development and advancement of biomaterials, which have included stem cells, cytokines, as well genetically manufactured components. It is my hope as a scientist, researcher and clinician, that the next decade will see tissue regenerative products, which may be stored in mass, rapidly deployed, and successfully applied to most wound types in almost any environment. I believe that off the shelf tissue regenerative materials are within our reach in the near future.
Copyright: (C)2018 Zhu Y. This is an open-access article distributed under the terms of the Creative Commons Attribution License, which permits unrestricted use, distribution, and reproduction in any medium, provided the original author and source are credited.
${ }^{\star}$ Correspondence to: Gerit Mulder, Department of Surgery and Orthopedics, University of California San Diego, USA, E-mail: gdmulder@ucsd.edu

Received: March 20, 2018; Accepted: March 28, 2018; Published: March 31, 2018 